\title{
Kualitas Semen Segar Kuda (Equus caballus) di Kabupaten Deli Serdang
}

\author{
Semen Quality of The Stallion (Equus caballus) in Deli Serdang District \\ I. P. Sari' ${ }^{1}$ N. D. Hanafi ${ }^{2}$ Hamdan $^{2}$ dan F. Hasan ${ }^{2}$ \\ ${ }^{1}$ Mahasiswa Program Studi Peternakan, Fakultas Pertanian, Universitas Sumatera utara \\ ${ }^{2}$ Dosen Program Studi Peternakan, Fakultas Pertanian, Universitas Sumatera Utara \\ E-mail corresponden author: Permatasariindah643@yahoo.com
}

\begin{abstract}
The fresh semen evaluation is very important for stallion before doing artificial insemination. This study aims to determine the quality of semen of the stallion in Deli Serdang regency and semen test at the Regional Artificial Insemination Center, North Sumatera in August-September 2017. This study was conducted on 10 male stallions aged 2-4 years in the district. then the data in show in the form of descriptive. The results showed that in macroscopic test the color of cement is white gray, consistency is watery, $\mathrm{pH}$ equal to $6.7 \pm \mathbf{0 . 4 8}$. In motility microscopic test (M\%) of $69 \pm 0.1$, concentrations of $\mathbf{1 3 4 . 5} \pm$ $0.94 \times 107$ / ml, and sperm condition 80\% normal. Based on motility (M\%) and concentration of semen quality with progressive spermatozoa movement and concentration of 134.5 million / $\mathrm{ml}$ of good horse to be superior male.
\end{abstract}

Keywords : stallion, quality, semen , macroscopic, microscopic

\section{PENDAHULUAN}

Populasi ternak kuda di Sumatera Utara sepuluh tahun terakhir yang tertinggi pada tahun 2006 yaitu populasi kuda mencapai 4.053 ekor, sedangkan yang terendah pada tahun 2015 dengan jumlah populasi kuda sekitar 1.917 ekor. Penurunan tersebut diduga terkait dengan tingginya angka pemotongan yang didorong oleh kesulitan ekonomi peternak, pengafkiran oleh berbagai sebab, dan rendahnya angka kelahiran. Beberapa kabupaten yang memiliki jumlah populasi kuda terbesar di Sumatera Utara diantaranya Kabupaten Karo dengan jumlah sekitar 94 ekor, Kabupaten Humbang Hasundutan dengan jumlah sekitar 488 ekor, dan Kabupaten Tapanuli Utara dengan jumlah sekitar 126 ekor (BPS, 2016). Populasi kuda di Kabupaten Deli Serdang juga sangat banyak dengan jumlah 96 ekor.

Beberapa kabupaten di Sumatera Utara memiliki potensi dalam memelihara ternak kuda, namun dalam pemeliharaan yang diterapkan masyarakat di daerah tersebut tidak maksimal dan efisien. Hal ini berdampak terhadap pertumbuhan dan perkembangbiakan dari ternak kuda tersebut tidak berjalan dengan baik. Berdasarkan pengamatan dilapangan banyak populasi ternak kuda jantan tidak sebanding dengan banyaknya jumlah betina. Setiap kabupaten terdapat 1-3 ekor kuda, dan jumlah betina 3050 ekor betina. Hal yang memprihatinkan diketahui bahwa satu ekor jantan mengawini seluruh populasi betina. Hal ini sudah terjadi selama bertahun-tahun, bila hal ini dilakukan terus menerus dapat mengakibatkan kerusakan keragaman genetik dari ternak kuda itu.
Beberapa peternak juga mengawinkan ternak kuda betina mereka ke luar daerah dan mendatangkan kuda jantan dari Australia guna memperbaiki kualitas genetik dimasa depan. Maka dari itu perlu dilakukan beberapa pengujian baik dari segi reproduksi dan produksi dari ternak kuda jantan di Kabupaten Deli Serdang. Salah satu cara untuk memprediksi kesuburan pejantan adalah dengan melihat daya simpan (longevity) semen segar, penyimpanan suhu ruang, semen segar dianggap baik apabila motilitas setelah 3 dan 8 jam minimal adalah 45 dan 10\% (Morel, 1999).

Penelitian tentang kualitas semen segar melalui uji mikroskopis dan makroskopis pada kuda di Kabupaten Deli Serdang perlu dilakukan untuk meningkatkan jumlah populasi kuda di Kabupaten Deli Serdang melalui program inseminasi buatan .

\section{MATERI DAN METODE}

Penelitian dilakukan di Desa Lou Bakeri Kecamatan Kutalimbaru dan Desa Jati Kesuma Kecamatan Namo Rambe di Kabupaten Deli Serdang dan pemeriksaan semen dilakukan di Laboratorium Balai Inseminasi Buatan Daerah (BIBD) Provinsi Sumatera Utara di Kota Medan pada bulan Agustus-September 2017. Semen dikoleksi dari 10 ekor kuda jantan yang berumur 3-4 tahun. Analisis data yang digunakan dalam penelitian ini adalah data kuantitatif dengan perhitungan ukuran reproduksi, ukuran pemusatan meliputi koefisien keragaman, rataan, dan simpangan baku yang didapat dari masing-masing parameter. Data yang didapat kemudian diolah dalam 3 bentuk rumus yaitu: 
1. Rumus perhitungan rata-rata

$$
\bar{X}=\frac{\sum_{i-1}^{n} x i}{n}
$$

2. Rumus perhitungan simpangan baku (Standard deviation)

$$
S=\frac{\sum_{n-1}^{n}(x i-\bar{x})}{n-1}
$$

3. Rumus perhitungan koefisien keragaman

$$
K K=\frac{S}{\bar{X}} X 100 \%
$$

Keterangan :

$\mathrm{X}$ : rata-rata

$\mathrm{S}$ : simpangan baku

$\mathrm{Xi}$ : ukuran ke-i dari peubah $\mathrm{x}$

$\mathrm{n} \quad$ : jumlah sampel yang diambil dari populasi

KK : koefisien Keragaman

\section{Peubah/parameter yang diamati}

Kualitas semen yang di uji secara makroskopis dan mikroskopis. Dimana makroskopis meliputi warna, kekentalan dan $\mathrm{pH}$. Pengamatan mikroskopis meliputi motilitas, konsentrasi, dan abnormalitas

\section{Prosedur Pengukuran Penampungan Semen}

Penampungan semen dilakukan dengan cara menampung semen dari luar alat kelamin jantan dengan asumsi keakuratan 80\%. Penampungan tidak dilakukan menggunakan vagina buatan melainkan menggunakan wadah yang steril. Semen yang diambil merupakan sampel semen. Dimana setelah dilakukannya perkawinan dengan betina semen yang masih terdapat dalam penis kuda di tampung.

\section{Evaluasi Makroskopis}

Makroskopis berupa pengukuran warna, kekentalan dan $\mathrm{pH}$ yang dilakukan dengan melihat dan memeriksa kondisi semen secara langsung ketika semen segar baru saja dikeluarkan dengan kriteria-kriteria penilaian yang sudah ditentukan. Warna semen diketahui langsung segera setelah penampungan karena tabung penampung mempunyai skala dan berwarna transparan. Konsistensi semen diketahui dengan memiringkan secara perlahan semen di dalam tabung penampung dan mengembalikan ke posisi semula sehingga diketahui kecepatan cairan kembali ke posisi semula. Derajat keasaman $(\mathrm{pH})$ diukur dengan meneteskan semen pada kertas indikator lakmus (skala $\mathrm{pH}$ 6,4-8,0), sehingga perubahan warna pada kertas dapat dibandingkan dengan warna standar.

\section{Evaluasi Mikroskopis}

Mikroskopis berupa motilitas, konsentrasi, dan abnormalitas spermatozoa yang dilakukan di laboratorium dengan pengamatan menggunakan mikroskop, dan bantuan beberapa peralatan tambahan berupa haemocytometer. Untuk mengethaui motilitas, sampel semen dan $\mathrm{NaCl}$ fisiologis diteteskan pada permukaan gelas objek (sekitar 1:3). Selanjutnya diaduk perlahan, ditutup dengan gelas penutup dan diamati dengan mikroskop cahaya perbesaran 10x40. Penilaian \% M didasarkan pada persentase spermatozoa yang bergerak ke depan pada beberapa lapang pandang.

Untuk mengetahui konsentrasi spermatozoa dihitung pada lima kotak arah diagonal atau empat kotak ditiap sudut dan satu kotak ditengah, hasil perhitungan tersebut dikalikan dengan 10 juta sama dengan konsentrasi spermatozoa / $\mathrm{ml}$. Total spermatozoa dalam satu ejakulat dihitung dengan mengalikan volume dengan konsentrasinya.

Sedangkan untuk mengetahui abnormalitas pada semen dilakukan dengan pewarna diferensial eosinnegrosin 2\%. Spermatozoa dinilai secara morfologi normal atau tidak, pada bagian kepala (abnormalitas primer), leher dan ekor (abnormalitas sekunder).

\section{HASIL DAN PEMBAHASAN}

\section{Kualitas Semen Kuda Secara Makroskopis}

Rataaan, simpangan baku dan koefisien keragaman dari ukuran makroskopis semen kuda jantan disajikan dalam Tabel 1. Jumlah kuda yang diamati adalah 10 ekor. Uji secara makroskopis meliputi warna, kekentalan dan pH. Uji ini dilakukan secara langsung dilapangan. Hasil persentase untuk warna yang didapat berdasarkan tabel tersebut yaitu $70 \%$ putih kelabu, $20 \%$ putih terang dan $10 \%$ putih kekuningan. Dimana secara umum warna yang didapatkan putih kelabu. Hal ini sesuai dengan pernyataan Yudi et al. (2008) yang menyatakan bahwa semen segar kuda mempunyai volume tanpa gel 29,3 \pm 9,3 mL, $\mathrm{pH} 7,0$ $\pm 0,1$, konsistensi encer, berwarna putih-susu. Begitu juga pernyataan Ferdis (2010) yang menyatakan semen babi dan kuda menyerupai larutan kanji (abu-abu encer). Toelihere (1993) yang menyatakan bahwa semen kuda dan babi cukup encer berwarna terang sampai kelabu.

Nilai persentase kekentalan (konsistensi) yang dihasilkan dari penelitian adalah 70\% encer dan 30\% kental. Dimana secara umum konsistensi semen yang didapatkan encer. Menurut Hafez \& Hafez (2000) konsistensi semen tergantung dari fraksi yang ditampung, fraksi praspermatozoa encer (watery), kaya-spermatozoa seperti susu tidak kental (milky, nonviscous), dan pasca-spermatozoa sangat kental (highly viscous). Toelihere (1993), mengatakan bahwa semen kuda jauh lebih encer daripada semen sapi dan domba. semen kuda dan babi merupakan cairan yang lebih voluminous dan lebih putih karena konsentrasi sperma rendah. Meskipun konsistensi yang didapatkan encer, bukan berarti kualitas semen kudanya tidak bagus. Kerena secara umum masih dalam kisaran normal untuk kuda.

Hasil penelitian menunjukkan bahwa seluruh semen mempunyai $\mathrm{pH}$ relatif netral, dengan rataan $6,70 \pm 0,48$ dan KK 7,82\%. Hasil ini tidak berbeda dengan Morel (1999) yang menyatakan bahwa $\mathrm{pH}$ semen kuda adalah berkisar 6,20-7,80. Sama halnya dengan hasil penelitian Yudi et al. (2007) rataan $\mathrm{pH}$ yang di dapatkan yaitu 7,00 $\pm 0,12$. 
Tabel 1. Rataan, simpangan baku dan koefisien keragaman dari uji makroskopis semen kuda

\begin{tabular}{cccc}
\hline \multirow{2}{*}{ No Kuda } & \multicolumn{3}{c}{ Makroskopis Semen } \\
\cline { 2 - 4 } & Warna & Kekentalan & $\mathrm{pH}$ \\
\hline 1 & Putih kelabu & Encer & 7 \\
2 & Putih terang & Encer & 6 \\
3 & Putih Kelabu & Kental & 7 \\
4 & Putih kekuningan & Kental & 6 \\
5 & Putih kelabu & Kental & 6 \\
6 & Putih kelabu & Encer & 7 \\
7 & Putih terang & Encer & 7 \\
8 & Putih kelabu & Encer & 7 \\
9 & Putih kelabu & Encer & 7 \\
10 & Putih kelabu & Encer & 7 \\
Persentase & $70 \%$ Putih Kelabu, & $70 \%$ Encer, & - \\
& $20 \%$ putih terang, & $30 \%$ kental & \\
Rata-rata & - & & 6,7 \\
SB & - & & \\
KK & - & & \\
\hline
\end{tabular}

\section{Kualitas Semen Kuda Secara Mikroskopis}

Rataan, simpangan baku dan koefisien keragaman dari data mikroskopis disajikan dalam Tabel 2, Uji mikroskopis meliputi motilitas, konsentrasi, dan abnormalitas, pengujian ini dilakukan di laboratorium Balai Inseminasi Buatan Daerah (BIBD).

Dari Tabel 2, rataan Motilitas yang di dapat adalah $69 \pm 0,1 \%$ dan koefisien keragaman $14,64 \%$. Hasil ini relatif sama dengan Toelihere (1993) yang mendapatkan motilitas sebesar 65\%, serta Yudi et al. (2007) sebesar 67,08 $99,08 \%$. Arifiantini et al. (2007) mendapatkan persentasi motilitas spermatozoa progesif sebesar $67,1 \pm 7,20 \%$ Presentasi motilitas dapat dikategorikan semen tersebut dalam keadaan baik dan berada dalam kelompok pergerakan yang progresif dan menghasilkan gerakan masa. Hal ini disesuaikan berdasarkan penilaian motilitas Toelihere (1993) yang menyatakan bahwa menentukan kualitas semen berdasarkan motilitas spermatozoa dengan nilai 0 sampai 5 . Spermatozoa kuda normal umumnya mempunyai derajat motilitas 3 sampai 4, dan 48 sampai $75 \%$ sperma di dalam bergerak aktif.

Konsentrasi dapat diartikan dengan jumlah spermatozoa yang terdapat disetiap mililiter semen, angka menunjukkan rataan nilai konsentrasi $(13,452 \pm 0,94 \%)$ x $10^{7} /$ $\mathrm{ml}$, dengan koefisien keragaman 6,99\%. Hasil konsentrasi yang didapatkan relatif lebih kecil dengan pernyataan Yudi et al. (2007) yang menyatakan bahwa konsentrasi semen kuda adalah $(211,88 \pm 21,15) \times 10^{7} / \mathrm{ml}$. Dan lebih tinggi dari pernyataan Toelihere (1993) yang menyatakan konsentrasi sperma kuda berkisar antara 30-600 juta sel per ml, dengan rata-rata 120 juta sel per $\mathrm{ml}$ semen. Perbedaan konsentrasi ini tergantung pada kapasitas individual, tingkatan makanan dan frekuensi pemakaian pejantan. Salisbury dan Van
Tabel 2. Rataan, simpangan baku dan koefisien keragaman dari uji mikroskopis semen kuda

\begin{tabular}{|c|c|c|c|}
\hline \multirow[t]{3}{*}{ No Kuda } & \multicolumn{3}{|c|}{ Mikroskopis Semen } \\
\hline & \multirow[t]{2}{*}{ Motilitas } & Konsentrasi & \multirow[t]{2}{*}{ Kondisi } \\
\hline & & $\left(\mathrm{x} 10^{7}\right)$ & \\
\hline 1 & $80 \%$ & 15,00 & Normal \\
\hline 2 & $70 \%$ & 12,96 & Normal \\
\hline 3 & $60 \%$ & 13,80 & Abnormal \\
\hline 4 & $65 \%$ & 13,20 & Normal \\
\hline 5 & $50 \%$ & 12,00 & Abnormal \\
\hline 6 & $60 \%$ & 14,16 & Normal \\
\hline 7 & $80 \%$ & 14,40 & Normal \\
\hline 8 & $75 \%$ & 13,80 & Normal \\
\hline 9 & $79 \%$ & 12,60 & Normal \\
\hline 10 & $70 \%$ & 12,60 & Normal \\
\hline Persentase & - & - & $80 \%$ Normal, \\
\hline & & & $20 \%$ Abnormal \\
\hline Rata-rata & $69 \%$ & 13.452 & - \\
\hline SB & 0,1 & 0,94 & \\
\hline KK $(\%)$ & $14,64 \%$ & $6,99 \%$ & \\
\hline
\end{tabular}

Demark (1985) menyatakan konsentrasi spermatozoa akan mengikuti perkembangan seksual dan kedewasaan, kualitas pakan yang diberikan, kesehatan alat reproduksi, besar testis, umur dan frekuensi ejakulasi pejantan.

Hasil analisis di laboratorium di dapatkan tingkat abnormalitas semen kuda adalah normal/ padat pengelompokan ini dikarenakan konsentrasi dari semen berada di kisaran $(13,452 \pm 0,94 \%) \times 10^{7} / \mathrm{ml}$ yang menandakan bahwa spermatozoa berada di kategori padat. Hal ini sesuai dengan pernyataan Toelihere (1993) yang menyatakan bahwa Densum (D) atau padat, jika jarak antara dua kepala sperma kurang dari panjang satu kepala konsentrasi ditaksir lebih kurang 1000-2000 juta sel per ml semen. Namun penilaian morfologik sperma pada kuda lebih sulit dibandingkan ternak lainnya. Pada kuda infertilitas dapat terjadi tanpa adanya kelainan pada spermatozoa dan fertilitas kuda jantan tidak selalu dapat ditentukan berdasarkan pemeriksaan semen. Karena beberapa kuda jantan dapat memiliki sperma yang normal tetapi fertilitas yang rendah, sebaliknya beberapa kuda jantan yang sangat fertil dapat memiliki sperma abnormal yang cukup banyak. Selama pengamatan ditemukan beberapa bentuk spermatozoa yang memiliki bagian ekor yang bengkok (bent), ekor memanjang, kepala yang terlampau kecil, dan kepala yang memanjang. Gambar yang memperlihatkan kondisi semen dilihat dari mikroskop pembesaran $40 \times 10$ dapat dilihat pada Gambar 1. 


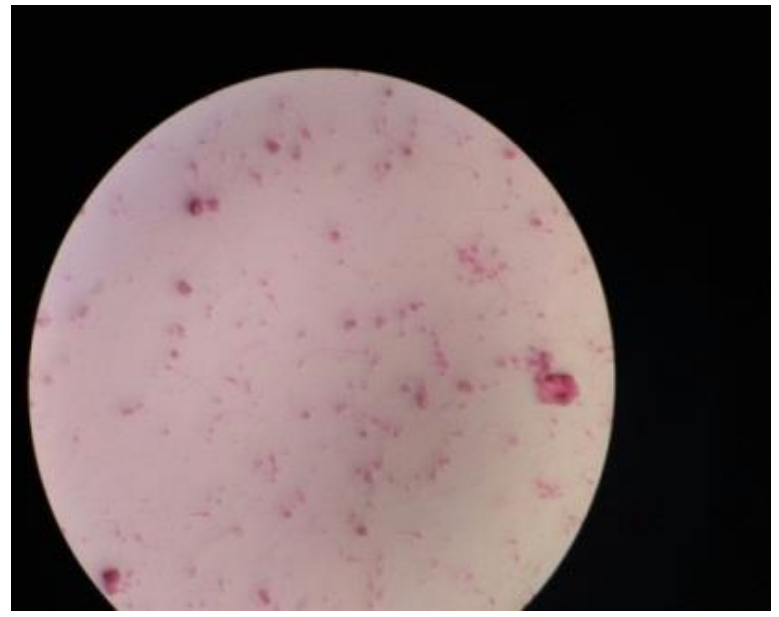

Gambar 1. Kondisi semen dilihat dari mikroskop (40x10)

\section{KESIMPULAN}

Kualitas semen segar cukup baik, dengan rataan warna putih kelabu, tingkat konsistensi encer, $\mathrm{pH}$ sebesar 6,7 $\pm 0,48$, Motilitas (M\%) sebesar 69 $\pm 0,1$, Konsentrasi sebesar $13,452 \pm 0,94 \times 10^{7} / \mathrm{ml}$, dan kondisi sperma $80 \%$ normal. Berdasarkan nilai motilitas (M\%), konsentrasi dan kualitas semen segar dengan pergerakan spermatozoa yang progresif dan konsentrasi 134,52 juta ml/ejakulat kuda baik untuk dijadikan pejantan di pusat inseminasi buatan.

\section{DAFTAR PUSTAKA}

Arifiantini, R.I., I. Supriatna dan Samsurizal. 2007. Penentuan Waktu Ekuilibrasi pada Pembekuan Semen Kuda Menggunakan Bahan Pengencer Susu Skim. Fakultas Kedokteran Hewan. Institut pertanian Bogor. Bogor

BPS Provinsi Sumatera Utara. 2016. Provinsi Sumatera Utara Dalam Angka 2016. Badan Pusat Statistika Provinsi Sumatera Utara. Medan

BPS Kabupaeten Deli Serdang. 2016. Kabupaten Deli Serdang Dalam Angka 2016. Badan Pusat Statistika Kabupaten Deli Serdang. Deli Serdang

BPS Kabupaten Karo. 2016. Kabupaten Karo Dalam Angka 2016. Badan Pusat Statistika Kabupaten Karo. Brastagi

BPS Kabupaten Humbang Hasundutan. 2016. Kabupaten Humbang Hasundutan Dalam Angka 2016. Badan Pusat Statistika Kabupaten Humbang Hasundutan. Dolok Sanggul

BPS Kabupaten Tapanuli Utara. 2016. Kabupaten Tapanuli Utara Dalam Angka 2016. Badan Pusat Statistika Kabupaten Tapanuli Utara. Tarutung

Feradis. 2010. Bioteknologi Reproduksi pada Ternak. Alfabveta. Bandung.

Grantino, F., U. Paputungan, Z. Poli, dan A. Lomboan. 2017. Perbandingan Morfometrik Kuda Di Kecamatan Tompaso Barat Dan Di Nusantara Polo Club Bogor Jawa Barat. Fakultas Peternakan. Universitas
Samratulangi

Hafez E.S.E. dan B. Hafez. 2000. Reproductive Cycle: Horses. In: E.S.E. Hafez \& B. Hafez (eds). Reproduction In Farm Animals. 7th ed. Lippincott Williams \& Wilkins, Philadelphia, USA

Kaban, H. 2017. Estimasi Jarak Genetik dan Faktor Peubah Pembeda Kuda di Sumatera Utara Melalui Analisis Morfometrik. Program Studi Peternakan. Fakultas Pertanian. Universitas Sumatera Utara. Medan

Morel, D.M.C.G. 1999. Equine Artificial Insemination. Oxon: CABI Publishing.

Salisbury, G. W. dan N. L. Van Denmark. 1985. Fisiologi dan Inseminasi Buatan pada Sapi (Physiologi and Artificial Insemination of Cattle). Diterjemahkan oleh Djanuar, R. Gajah Mada University Press. Yogyakarta.

Toelihere, M. R. 1981. Fisiologi Reproduksi Pada Ternak. Angkasa. Bandung.

Toelihere, M. R. 1993. Inseminasi Buatan Pada Ternak Cetakan ketiga. Angkasa. Bandung.

Yudi, I. Arifiantini, B. Purwantara, dan T. L.Yusuf. 2007. Karakteristik Semen Segar dan Kualitas Semen Cair Kuda dalam Pengencer Dimitropoulos yang Disuplementasi dengan Fruktosa, Trehalosa dan Rafinosa. Media Peternakan vol. 30 (3) : 163-172.

Yudi, I. Arifiantini, B. Purwantara, dan T. L.Yusuf. 2008. Daya Tahan Semen Segar dan Kualitas Semen Cair Kuda dengan Konsentrasi Spermatozoa Berbeda dalam Pengencer Dimitropoulos yang Dimodifikasi. JITV vol.13 (1) : 35-42. 